\title{
Grand Challenges in Environmental Systems Engineering
}

\author{
Can Wang* \\ State Key Joint Laboratory of Environment Simulation and Pollution Control, School of Environment, Tsinghua University, Beijing, \\ China
}

Keywords: global environmental issues, system engineering, uncertainty, multi-disciplinary, multi-disciplinary, cross-disciplinary

\section{INTRODUCTION}

The world is facing multiple environmental challenges simultaneously, such as environmental pollution, climate change, energy security, resource availability, ecosystem degradation, and biodiversity loss. Tackling these challenges has become increasingly complex due to the growing cross-temporal, cross-spatial, and cross-system human-environment interactions (Liu et al., 2015; Wang et al., 2019). Environmental Systems Engineering (ESE) applies systematic thinking and methods to simulate and manage the complex human-environment interactions, aiming to seek effective solutions for sustainable development. ESE research has made significant progress in the past few decades, including: 1) construction of comprehensive analysis framework; 2) identification of key drivers and boundaries of environmental systems change; 3) investigation of influencing mechanisms of human-nature interactions; 4) development of mathematical simulation and modeling methods; 5) integrated utilization of data from different sources; and 6) expansion of environmental systems modeling across spatial, temporal and organizational scales.

Despite the remarkable achievements, the ESE field still needs to be overcome several roadblocks. This brief paper focuses on three of them: 1) The integration of multiple temporal and spatial scales;

\section{OPEN ACCESS}

Edited and reviewed by: Martin Siegert,

Imperial College London, United Kingdom

${ }^{*}$ Correspondence: Can Wang

canwang@tsinghua.edu.cn

Specialty section:

This article was submitted to Environmental Systems Engineering,

a section of the journal

Frontiers in Environmental Science

Received: 05 November 2021 Accepted: 18 November 2021 Published: 06 December 2021

Citation: Wang C (2021) Grand Challenges in Environmental Systems Engineering.

Front. Environ. Sci. 9:809627.

doi: 10.3389/fenvs.2021.809627
2) the cross-disciplinary interactions and influence; and 3) the deep uncertainty in the non-linear dynamics of society-economy-environment systems. For each challenge, the paper examines the grand challenges and obstacles and presents priority areas for future research. The purpose of the paper is to call for more interest and endeavors in ESE, and facilitate significant progress and new breakthroughs towards sustainable development.

\section{ADDRESSING MULTIPLE SCALES OVER TIME AND SPACE}

Complexities in human-nature interactions exist across multiple spatial and temporal scales. From the spatial perspective, "telecoupling" has been recognized as one of the research hotpots in ESE (Lenschow et al., 2016). The term refers to the fact that environmental challenges are not limited to local or regional boundaries, but are global issues. On the one hand, environmental pollution can disseminate far away from its sources, driven by natural environmental vectors and the global flow of people, goods, information, energy, and materials. For instance, it is found that plastic trash has spread to remote or even inaccessible ocean islands, with the transport of ocean currents (Cózar et al., 2017). Another typical case is that tropical rainforest deforestation not only harms health and employment of local residents, but also exacerbates global climate change and related risks (Vargas Zeppetello et al., 2020). On the other hand, the globalization of human activities has led to situations where the production, consumption or the policies made in one place may enhance or harm the sustainability of other places. To reveal such spatial externalization effects of production and consumption, the environmental footprint family was developed (Wiedmann and Lenzen, 2018; 
Zheng et al., 2018). Such telecoupling drives ESE research to expand from regional scale considerations to those also at the global scale.

Human-nature interactions are complex over temporal scales. Due to the limitations of human cognition, many environmental problems with lagging effects are hard to detect in the short term (Milfont and Demarque, 2015). Decisions made today may have long-term, irreversible consequences in the future. A typical example is the carbon lock-in effect caused by existing and planned energy infrastructure, which committed carbon emissions in the next few decades (Seto et al., 2016). Identifying and informing the long-term and unintended consequences of such decisions is essential to avoid locking the system on an unsustainable path.

Incorporating the spatial externalization and temporal lagging effect of environmental issues into the analysis framework with higher resolution and across larger spatial-temporal scales, is thus an inevitable goal in the future of ESE. Two fundamental improvements are needed to achieve this. The first is to develop integrated observation systems (such as the Global Earth Observation System) and data sets combining both nature and human elements, which provide data for analysis at various spatialtemporal scales. The second is to develop multi-scale analysis framework and modeling methods; for instance, an integrated framework that couples macro policy analysis with micro behavior simulation (Elsawah et al., 2020). On the way to constructing such a framework, an advanced methodology, including up-scaling, and down-scaling methods to resolve mismatching problems among different sub-systems, must also be further developed.

\section{BRIDGING FRAMEWORKS AND METHODS ACROSS DISCIPLINES}

The multi-disciplinary nature of environmental issues is a fundamental grand challenge in ESE research. On the one hand, problem solving in environmental systems relies on the investigation of driving factors and policy interventions in human systems, requiring an integration of natural science and social science. Examples are: The factors that drive human demands for goods and services being at the center of greenhouse gas emissions and pollution control (Baiocchi et al., 2010); and cultural barriers and consumer awareness that can explain the gaps between the stated objective of policies and their realistic implementation effectiveness (Kirchherr et al., 2018). On the other hand, the multi-disciplinary connections mean that dealing with one environmental issue may cause associate effects on other systems. For example, the large-scale use of biofuels may cause cross-system impacts on land use, water scarcity, food supply and human health (Weng et al., 2019; Li et al., 2020). To address complex interactions across systems, a comprehensive assessment with multi-dimensional mindset, as well as an in-depth cooperation among discrete subjects (like earth system science, life science, ecology, and sociology) is in need (Wang et al., 2020).

Though inspiring progress on facilitating cross-disciplinary communication has been made, strictly speaking, researchers are still trapped in their own discipline, often lacking trust and open minds for how other disciplines may impact their own. Further integration of knowledge, methods and ideas from different subjects are necessary at three levels. The first is the integration of professional knowledge, theories and methods that straddle disciplines. This level of integration is relatively easy to achieve, thus it becomes the main contribution area of interdisciplinary research in ESE. For example, the framework of ecosystem services has been used to define ecological values from the economic perspective as a way to emphasize society's dependence on natural ecosystems (Braat and de Groot, 2012). The term "resilience" is used in various contexts, with similar meaning closely related with the capability to return to a stable state from disruption (Bhamra et al., 2011). In addition, quantitative models from different disciplines are soft-linked to solve more comprehensive problems (Krook-Riekkola et al., 2017). Despite the progress, we need to enhance model transparency and promote data sharing across and between disciplines. The second level of integration is to incorporate the interaction and feedback dynamics of different systems into the analysis framework, such as considering human adaptive behavior when assessing the impact of environmental pollution and natural disasters (Di Baldassarre et al., 2015), and considering cultural contexts and social norms when designing policy tools to tackle with sustainability problems (Zheng et al., 2021). This level of integration is more challenging due to the complexity and uncertainty of human activities and multiple interacting influencing factors. The third level is the recognition and appreciation of diverse ideologies in different subjects. Researchers in different fields often lack trust in the rationality of research ideas and methods from other disciplines, which hinders the bridge between various academic islands (Mooney et al., 2013). For example, natural science research focuses on quantitative analysis and usually overlooks the value of qualitative assessment that is often used in social science research. Acknowledging the diversity of knowledge itself is both rather challenging yet critical to solving major environmental problems.

\section{MANAGING DEEP UNCERTAINTIES FROM SYSTEMATIC CHANGES}

Interactive environmental and socioeconomic systems are each undergoing interrelated dynamical changes. According to theory in system dynamics, quantitative models can be used to capture key processes in environmental system dynamics and their interactions with socioeconomic systems, aiming to predict future trends based on the changing patterns in the past. However, most changes in reality are non-linear, especially when the system undergoes a sudden, substantial and irreversible transition. This non-linear change causes large uncertainty in extrapolation and projection. There are numerous examples of systematic nonlinear changes in the environmental field, such as ecological collapse caused by lake eutrophication, desertification, and ocean acidification (Moore, 2018). To learn more about such systematic changes, existing research has focused on identifying risk thresholds, for example, in the quantification of planetary boundaries (Rockström et al., 2009). Additionally, socio-economic systems also experience 
systemic changes brought by unexpected incidents such as regime changes, institutional changes, the introduction of disruptive technologies, and financial crises etc. Compared with natural systems, systematic changes in social economics are often more frequent and more difficult to predict because of unknown events and "black swan" events like the COVID-19 epidemic.

Traditional uncertainty analysis in ESE modeling focuses on three aspects: Data quality, appropriate model structure and confidence in model parameters. Such analysis fails to address the endogenous problems caused by the nonlinear dynamics, however (Lempert, 2002). In order to enable analysis on deep uncertainty and better support policy decisions, the following potential research directions are recommended in future ESE research:

- acquiring larger-scale and higher-resolution socioeconomic and natural system observation data (e.g., relying on new data types and sources from social media, mobile phones, satellite remote sensing, and sensors, etc.);

- investigating the driving factors and influencing mechanisms of nonlinear changes in the system;

- developing exploratory modeling and analysis (Kwakkel and Pruyt, 2013) based on richer future scenario settings and incorporating the simulation of adaptive feedback dynamics;

- and enhancing the understanding of modelers and stakeholders on various uncertainty sources (Mielke et al., 2017), and develop participatory modeling (Jones et al., 2009) to extend uncertainty management from model simulation to management practice.

\section{REFERENCES}

Baiocchi, G., Minx, J., and Hubacek, K. (2010). The Impact of Social Factors and Consumer Behavior on Carbon Dioxide Emissions in the United Kingdom. J. Ind. Ecol. 14, 50-72. doi:10.1111/j.1530-9290.2009.00216.x

Bhamra, R., Dani, S., and Burnard, K. (2011). Resilience: the Concept, a Literature Review and Future Directions. Int. J. Prod. Res. 49, 5375-5393. doi:10.1080/ 00207543.2011.563826

Braat, L. C., and de Groot, R. (2012). The Ecosystem Services Agenda:bridging the Worlds of Natural Science and Economics, Conservation and Development, and Public and Private Policy. Ecosystem Serv. 1, 4-15. doi:10.1016/j.ecoser.2012.07.011

Cózar, A., Martí, E., Duarte, C. M., García-de-Lomas, J., Van Sebille, E., Ballatore, T. J., et al. (2017). The Arctic Ocean as a Dead End for Floating Plastics in the North Atlantic branch of the Thermohaline Circulation. Sci. Adv. 3, e1600582. doi:10.1126/sciadv.1600582

Di Baldassarre, G., Viglione, A., Carr, G., Kuil, L., Yan, K., Brandimarte, L., et al. (2015). Debates- Perspectives on Socio-Hydrology: Capturing Feedbacks Between Physical and Social Processes. Water Resour. Res. 51, 4770-4781. doi:10.1002/2015WR017046

Elsawah, S., Filatova, T., Jakeman, A. J., Kettner, A. J., Zellner, M. L., Athanasiadis, I. N., et al. (2020). Eight Grand Challenges in Socio-Environmental Systems Modeling. Sesmo. 2, 16226. doi:10.18174/sesmo.2020a16226

Jones, N. A., Perez, P., Measham, T. G., Kelly, G. J., d'Aquino, P., Daniell, K. A., et al. (2009). Evaluating Participatory Modeling: Developing a Framework for Cross-Case Analysis. Environ. Manage. 44, 1180-1195. doi:10.1007/s00267-009-9391-8

Kirchherr, J., Piscicelli, L., Bour, R., Kostense-Smit, E., Muller, J., HuibrechtseTruijens, A., et al. (2018). Barriers to the Circular Economy: Evidence From the European Union (EU). Ecol. Econ. 150, 264-272. doi:10.1016/ j.ecolecon.2018.04.028
The complement of such work requires wider international cooperation on mutual use of information systems and data, more financial support for knowledge exchange, and active policy involvement in scientific research. Although challenging, the work is meaningful as it would deliver enhanced modeling ability and deeper research-policy integration in ESE.

\section{CONCLUDING REMARKS}

This short paper addresses three major challenges and the corresponding priority research areas in ESE: The complexity of human-nature system across various spatial-temporal scales; the integration of multiple disciplines; and the deep uncertainties resulting from nonlinear dynamics. It is worth mentioning that these areas of future research are not isolated from each other. In most cases, they need to be addressed simultaneously. For example, interdisciplinary research across multiple spatialtemporal scales often has the problem of scaling mismatch among subsystems, and the spatial/temporal scale selection will significantly affect the uncertainty of the model. A growing community needs to be better connected and governed if it is to deliver more progress and breakthroughs in the ESE field by addressing these challenges.

\section{AUTHOR CONTRIBUTIONS}

The author confirms being the sole contributor of this work and has approved it for publication.

Krook-Riekkola, A., Berg, C., Ahlgren, E. O., and Söderholm, P. (2017). Challenges in Top-Down and Bottom-Up Soft-Linking: Lessons from Linking a Swedish Energy System Model With a CGE Model. Energy. 141, 803-817. doi:10.1016/ j.energy.2017.09.107

Kwakkel, J. H., and Pruyt, E. (2013). Exploratory Modeling and Analysis, an Approach for Model-Based Foresight Under Deep Uncertainty. Technol. Forecast. Soc. Change. 80, 419-431. doi:10.1016/j.techfore.2012.10.005

Lempert, R. J. (2002). A New Decision Sciences for Complex Systems. Proc. Natl. Acad. Sci. 99, 7309-7313. doi:10.1073/pnas.082081699

Lenschow, A., Newig, J., and Challies, E. (2016). Globalization's Limits to the Environmental State? Integrating Telecoupling into Global Environmental Governance. Environ. Polit. 25, 136-159. doi:10.1080/09644016.2015.1074384

Li, J., Cai, W., Li, H., Zheng, X., Zhang, S., Cui, X., et al. (2020). Incorporating Health Cobenefits in Decision-Making for the Decommissioning of Coal-Fired Power Plants in China. Environ. Sci. Technol. 54, 13935-13943. doi:10.1021/ acs.est.0c03310

Liu, J., Mooney, H., Hull, V., Davis, S. J., Gaskell, J., Hertel, T., et al. (2015). Sustainability. Systems Integration for Global Sustainability. Science. 347, 1258832. doi: $10.1126 /$ science. 1258832

Mielke, J., Vermaßen, H., and Ellenbeck, S. (2017). Ideals, Practices, and Future Prospects of Stakeholder Involvement in Sustainability Science. Proc. Natl. Acad. Sci. 114, E10648. doi:10.1073/pnas.1706085114

Milfont, T. L., and Demarque, C. (2015). Understanding Environmental Issues With Temporal Lenses: Issues of Temporality and Individual Differences. Proc. Natl. Acad. Sci. USA. 114, 371-E10657. doi:10.1073/pnas.1706085114

Mooney, H. A., Duraiappah, A., and Larigauderie, A. (2013). Evolution of Natural and Social Science Interactions in Global Change Research Programs. Proc. Natl. Acad. Sci. 110, 3665-3672. doi:10.1073/pnas.1107484110

Moore, J. C. (2018). Predicting Tipping Points in Complex Environmental Systems. Proc. Natl. Acad. Sci. USA. 115, 635-636. doi:10.1073/pnas.1721206115 
Rockström, J., Steffen, W., Noone, K., Persson, Å., Chapin, F. S., Lambin, E., et al. (2009). Planetary Boundaries Exploring the Safe Operating Space for Humanity. Ecol. Soc. 14. doi:10.5751/ES-03180-140232

Seto, K. C., Davis, S. J., Mitchell, R. B., Stokes, E. C., Unruh, G., and ÜrgeVorsatz, D. (2016). Carbon Lock-In: Types, Causes, and Policy Implications. Annu. Rev. Environ. Resour. 41, 425-452. doi:10.1146/ annurev-environ-110615-085934

Vargas Zeppetello, L. R., Parsons, L. A., Spector, J. T., Naylor, R. L., Battisti, D. S., Masuda, Y. J., et al. (2020). Large Scale Tropical Deforestation Drives Extreme Warming. Environ. Res. Lett. 15, 084012. doi:10.1088/1748-9326/ab96d2

Wang, C., Guan, D., and Cai, W. (2019). Grand Challenges Cannot Be Treated in Isolation. One Earth. 1, 24-26. doi:10.1016/j.oneear.2019.08.005

Wang, C., Huang, H., Cai, W., Zhao, M., Li, J., Zhang, S., et al. (2020). Economic Impacts of Climate Change and Air Pollution in China Through Health and Labor Supply Perspective: an Integrated Assessment Model Analysis. Clim. Change Econ. 11, 2041001. doi:10.1142/s2010007820410018

Weng, Y., Chang, S., Cai, W., and Wang, C. (2019). Exploring the Impacts of Biofuel Expansion on Land Use Change and Food Security Based on a Land Explicit CGE Model: A Case Study of China. Appl. Energ. 236, 514-525. doi:10.1016/j.apenergy.2018.12.024

Wiedmann, T., and Lenzen, M. (2018). Environmental and Social Footprints of International Trade. Nat. Geosci. 11, 314-321. doi:10.1038/s41561-0180113-9
Zheng, X., Wang, R., Hoekstra, A. Y., Krol, M. S., Zhang, Y., Guo, K., et al. (2021) Consideration of Culture Is Vital if We Are to Achieve the Sustainable Development Goals. One Earth. 4, 307-319. doi:10.1016/j.oneear.2021.01.012 Zheng, X., Wang, R., Wood, R., Wang, C., and Hertwich, E. G. (2018). High Sensitivity of Metal Footprint to National GDP in Part Explained by Capital Formation. Nat. Geosci. 11, 269-273. doi:10.1038/s41561-018-0091-y

Conflict of Interest: The author declares that the research was conducted in the absence of any commercial or financial relationships that could be construed as a potential conflict of interest.

Publisher's Note: All claims expressed in this article are solely those of the authors and do not necessarily represent those of their affiliated organizations, or those of the publisher, the editors and the reviewers. Any product that may be evaluated in this article, or claim that may be made by its manufacturer, is not guaranteed or endorsed by the publisher.

Copyright (C) 2021 Wang. This is an open-access article distributed under the terms of the Creative Commons Attribution License (CC BY). The use, distribution or reproduction in other forums is permitted, provided the original author(s) and the copyright owner(s) are credited and that the original publication in this journal is cited, in accordance with accepted academic practice. No use, distribution or reproduction is permitted which does not comply with these terms. 